\title{
Cytisine induces endoplasmic reticulum stress caused by calcium overload in HepG2 cells
}

\author{
LEI YU ${ }^{1-3}$, BO JIANG ${ }^{1-3}$, ZHIFENG CHEN $^{2}$, XIN WANG $^{1-3}$, DONGXUE SHANG $^{1-3}$, \\ XIAOPO ZHANG ${ }^{4}$, YONGXUE SUN ${ }^{1-3}$, JINGHUI YANG ${ }^{1-3}$ and YUBIN JI ${ }^{1-3}$

\footnotetext{
${ }^{1}$ Center of Research and Development on Life Sciences and Environmental Sciences, Harbin University of Commerce;

${ }^{2}$ Institute of Materia Medica and Postdoctoral Programme of Harbin University of Commerce;

${ }^{3}$ Engineering Research Centre of Natural Anticancer Drugs, Ministry of Education, Harbin, Heilongjiang 150076;

${ }^{4}$ School of Pharmaceutical Sciences, Hainan Medicinal University, Haikou, Hainan 571199, P.R. China
}

Received June 29, 2017; Accepted January 2, 2018

DOI: 10.3892/or.2018.6200

\begin{abstract}
Cytisine, a quinolizidine alkaloid, is one of the major bioactive components found in the small tree Sophora Alopecuraides L., and is a traditional Chinese medicine that is used for treating hepatitis and liver cancer. In the 1960s, quinolizidine alkaloids were reported to exhibit inhibitory effects on tumour cell proliferation in several types of cancer cells. However, few studies have investigated the effect of cytisine on liver cancer. Our team confirmed that cytisine induced apoptosis in HepG2 cells via a mitochondrial pathway. The primary aim of the present study was to evaluate the endoplasmic reticulum (ER) stress caused by calcium overload in cytisine-induced apoptosis in HepG2 cells and the molecular mechanisms of this phenomenon. In addition, the present study was undertaken to evaluate the expression of $\alpha 7-n A C h R$ when apoptosis was induced by cytisine in HepG2 cells. In the present study, transmission electron microscopy was used to observe the morphological appearance of HepG2 cells. The apoptosis of the cells with cytoplasmic vacuolization was significant under electron microscopy. Apoptotic bodies, the expansion of the ER,
\end{abstract}

Correspondence to: Dr Lei Yu, Center of Research and Development on Life Sciences and Environmental Sciences, Harbin University of Commerce, 138 Tongda Street, Harbin, Heilongjiang 150076, P.R. China

E-mail: yulei912@163.com

Professor Xiaopo Zhang, School of Pharmaceutical Sciences, Hainan Medicinal University, Haikou, Hainan 571199, P.R. China

E-mail: z_xp1412@163.com

Abbreviations: PI, propidium iodide; ER, endoplasmic reticulum; nAChRs, nicotinic acetylcholine receptors; UPR, unfolded protein response; EOR, endoplasmic reticulum overload response; HCPT, 10-hydroxycamptothecin; SDS-PAGE, sodium dodecyl sulphate-polyacrylamide gel electrophoresis

Key words: cytisine, HepG2 cells, apoptosis, endoplasmic reticulum stress, calcium overload, CHOP pathway, JNK pathway and swelling of mitochondria were observed in the HepG2 cells after cytisine treatment. Flow cytometric analysis demonstrated that the apoptosis rate of HepG2 cells was upregulated. In addition, the intracellular calcium concentration was detected by laser confocal fluorescence microscopy. The laser confocal fluorescence microscopy showed that the calcium concentration was increased in a dose-dependent manner. The activity of caspase- 4 was evaluated by an enzyme-linked analyser, and the expression levels of CHOP, JNK, p-JNK and $\alpha 7-n A C h R$ were assessed via western blot analysis. In the present study, we observed that cytisine induced ER stress-inducing factors and CHOP and p-JNK1/2 protein expression, and it increased the JNK protein expression in the HepG2 cells. Furthermore, $\alpha 7-n A C h R$ protein expression was promoted in a dose-dependent manner after cytisine treatment. These findings suggest that cytisine induced the ER stress-mediated apoptotic pathway via activation of CHOP, JNK and caspase-4 in HepG2 cells, and cytisine is a potential new target compound for $n$ AchRs (nicotinic acetylcholine receptors) to treat liver cancer.

\section{Introduction}

Quinolizidine alkaloids have previously been demonstrated to exhibit antitumour activities in vitro and in vivo $(1,2)$. Cytisine, a quinolizidine alkaloid from Sophora Alopecuraides L., has been widely used for the treatment of central nervous system diseases. It has previously been demonstrated that cytisine may significantly inhibit neuronal apoptosis induced by NMDA exposure by reversing intracellular $\mathrm{Ca}^{2+}$ overload and balancing the expression levels of Bcl-2 and Bax (3). Furthermore, several in vitro studies have also confirmed the antitumour activities of cytisine. Cytisine was found to inhibit human cancer cell lines, including HepG2, A549, K562, Ec109, HL-60 and U937 cells (4). Our team confirmed the molecular mechanisms underlying cytisine-induced apoptosis of HepG2 via a mitochondrial pathway; however, the specific mechanism underlying endoplasmic reticulum (ER) stress remains to be elucidated.

Apoptosis is a crucial mechanism for cell clearance. It is now accepted that cell apoptosis has mainly three apoptotic 
signalling pathways, including the mitochondrial, the death receptor- and the ER-associated pathway (5-7). In recent years, researchers have discovered that ER stress-mediated apoptosis is a new signalling pathway for apoptosis (8). The endoplasmic reticulum (ER), a membrane-bound organelle, plays an essential role in eukaryotic cell processes, including synthesizing, sorting, assembling, modifying and trafficking proteins, and maintaining intracellular $\mathrm{Ca}^{2+}$ homeostasis (9). The normal functioning of the ER signalling cascades requires high concentrations of free calcium ions within the ER lumen. Impairment of $\mathrm{Ca}^{2+}$ homeostasis or other noxious stimuli may trigger an ER stress response that is manifested by either an unfolded protein response (UPR) or an ER overload response (EOR) within the ER lumen (10-13). However, if the stress persists on the ER for a longer period of time, the ER stress triggers cell death (typically apoptosis) mainly through three pathways, including CHOP (14), JNK (15) and caspase-12 (16-18). Although caspase-12 has been implicated in ER stress-induced apoptosis in rodents, it is controversial whether similar mechanisms operate in humans. Recent research has indicated that caspase-4, which is one of the closest paralogs of rodent caspase-12, plays an important role in cell death (19). Thus, the present study investigated the ER stress effects of cytisine on HepG2 cells in relation to CHOP, JNK and caspase-4.

Additional studies have indicated that cytisine can be used as an $\mathrm{nAChR}$ partial agonist in clinical use as a smoking cessation aid. Therefore, cytisine is considered to be superior to nicotine-replacement therapy for smoking cessation (20-22). Nicotinic acetylcholine receptors (nAChRs) consist of various types of subunits, such as $\alpha 2-\alpha 10, \beta 2-\beta 4$, which are a complex of five subunits forming hetero- or homo-pentamers that form a central ion channel. nAChRs were originally identified to be only expressed in the nervous system and at neuromuscular junctions (muscle type nAChRs). However, the discovery of widespread expression of $\mathrm{nAChRs}$ in the cell membrane of all mammalian cells, including cancer cells, suggested its direct role in the development and progression of cancers (23). Therefore, nAChRs are viewed as a novel drug target for the prevention and treatment of various forms of cancers. Recently, increasing evidence has shown that $\alpha-7$ nicotinic receptors exhibit the highest permeability for $\mathrm{Ca}^{2+}$, promoting cell death via a release of $\mathrm{Ca}^{2+}$ from intracellular stores and intracellular $\mathrm{Ca}^{2+}$ overloading $(24,25)$.

The major aim of the present study was to elucidate the the effects of cytisine on ER stress in HepG2 cells in terms of the intracellular calcium concentration and the three pathways involved in ER stress, including CHOP, JNK and caspase-4. Additionally, the present study investigated the effect of cytisine on the expression of $\mathrm{nAchR}$.

\section{Materials and methods}

Instruments and reagents. Cytisine (no. 20111101C; Shanxi River Pharmaceutical Co., Ltd., Xi'an, China); human hepatocellular carcinoma cell line, HepG2 (Life Sciences and Environmental Sciences Development Centre of Harbin University of Commerce, Harbin, China); RPMI-1640 medium (no. 20130507; Gibco Co., Carlsbad, CA, USA); fetal calf serum (FCS) (no. 20140206; Zhejiang Tianhang Biotechnology
Co., Ltd., Zhejiang, China); propidium iodide (PI) (no. P4170; Sigma Co., St. Louis, MO, USA); fluorescence microscope (Olympus Corporation, Tokyo, Japan); HCPT (no. H109197; Aladdin Reagent Co. Ltd., Shanghai, China); monoclonal antibody of $\beta$-actin (no. 141125), p-JNK (no. A1514) (both from ZSGB-BIO Co., Ltd., Beijing, China); monoclonal antibody of GADD153 (no. 980787W; Beijing Biosynthesis Biotechnology Co., Ltd., Beijing, China), JNK (no. 150116; Wanleibo Co., Ltd., Shanghai, China); caspase-4 test kit (no. 20140526; Beyotime Institute of Biotechnology, Haimen, China); JEM-1220 transmission electron microscope (JEOL Ltd.); EPICS XL-MCL flow cytometry (Beckman Coulter, Inc., Brea, CA, USA); 680 enzyme-linked analyser (Bio-Rad Laboratories, Inc., Hercules, CA, USA); peroxidase-conjugated AffiniPure goat anti-rabbit IgG (H+L; cat. no. ZB-2301) and peroxidase-conjugated AffiniPure goat anti-mouse IgG $(\mathrm{H}+\mathrm{L}$; cat. no. ZB-2305) (both from ZSGB-BIO Co., Ltd.).

Effect of cytisine on the morphological appearance of HepG2 cells. Transmission electron microscopy was used to observe the morphological appearance of the HepG2 cells after drug treatment (26). Cells were gently harvested after trypsin digestion and washed twice with PBS. Approximately $3 \times 10^{5}$ cells were treated in single wells of 6-well plates. The cultured HepG2 cells were exposed to cytisine at concentrations of 2.5, 5 and $10 \mathrm{mM}$, or they were exposed to HCPT at concentrations of $60 \mu \mathrm{M}$ for $24 \mathrm{~h}$ at $37^{\circ} \mathrm{C}$ with $5 \% \mathrm{CO}_{2}$. Since cytisine and HCPT both belong to the same family of alkaloids, HCPT was used as the positive drug in the present study to verify that the experimental method was correct. A blank control group was added with the same volume of RPMI-1640 culture medium, and the cells were collected after $24 \mathrm{~h}$. Next, $2 \%$ glutaraldehyde was used to fix the cells for $>2 \mathrm{~h}$, and they were immobilized with osmium acid. After alcohol gradient dehydration, all groups were treated with epoxy resin embedding, ultrathin sectioning, uranyl acetate and lead citric acid double staining and then imaged under the transmission electron microscope.

Apoptosis assays. Quantitative analysis of the apoptosis was evaluated via flow cytometry with PI staining according to prior guidelines (27). Cells were gently harvested after trypsin digestion and washed twice with PBS. The cells were then centrifuged at $1,000 \mathrm{rpm}$ for $10 \mathrm{~min}$. Cells $\left(1 \times 10^{6}\right)$ were treated approximately into a single cell suspension with PBS solution and fixed with $70 \%$ ice-cold ethanol at $4{ }^{\circ} \mathrm{C}$ overnight. Afterwards, the cells were washed twice with PBS and stained with a solution containing $800 \mu \mathrm{l}$ of PI (PI staining contains sodium citrate $33.4 \mathrm{mg}$, PI $5 \mathrm{mg}$, RNase A $1 \mathrm{mg}$, joined Triton X-100 $0.5 \mathrm{ml}$ ) for $30 \mathrm{~min}$ in the dark at room temperature. A minimum of 10,000 cells were maintained for all of the samples. The cells were later analysed for their DNA content using flow cytometry. By analysing the DNA histograms, the percentage of the cells in different cell cycle phases was evaluated using MyltiCycle for Windows 32-bit software (Beckman Coulter, Inc.). Finally, the cells with sub- $\mathrm{G}_{0} / \mathrm{G}_{1}$ DNA (sub- $\mathrm{G}_{1}$ ) were calculated as apoptotic cells. Apoptosis was recorded using the laser line of $488 / 630 \mathrm{~nm}$.

Confocal laser scanning microscope (CLSM) analysis. The accumulation of $\mathrm{Ca}^{2+}$ ions in the cytoplasm was studied using 
A

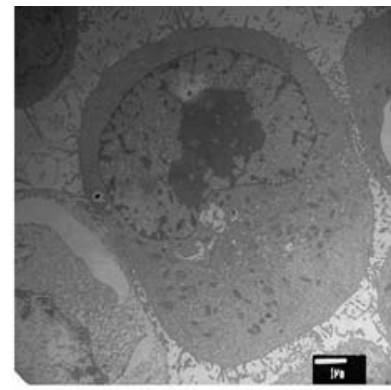

C

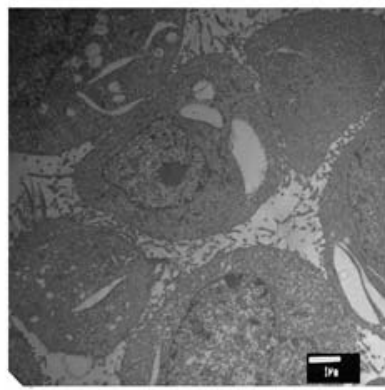

B
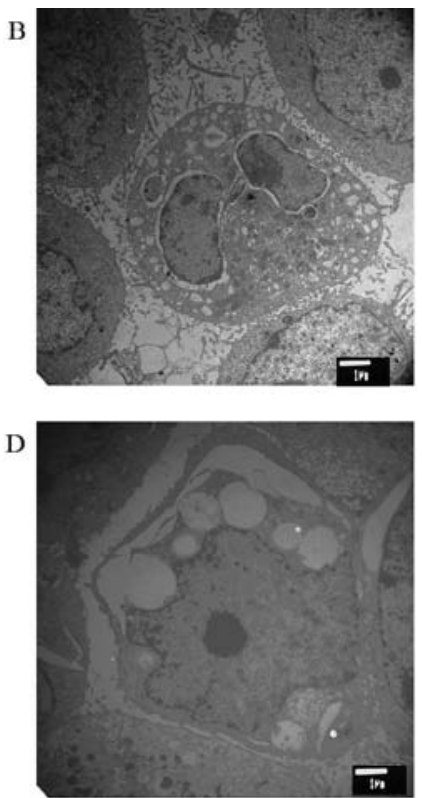



Figure 1. Effect of cytisine on the morphological appearance of HepG2 cells. In all groups, cells were observed by a transmission electron microscope. (A) HepG2 cells treated with RPMI-1640 medium. (B) HepG2 cells treated with $60 \mu \mathrm{M}$ HCPT. (C) HepG 2 cells treated with 2.5 mM cytisine. (D) HepG2 cells treated with $5 \mathrm{mM}$ cytisine. (E) HepG2 cells treated with $10 \mathrm{mM}$ cytisine.

the fluorescent dye, Fluo3 AM (28). Approximately, 3x10 5 cells were seeded per well in 6-well plates and incubated for $24 \mathrm{~h}$ before treatment with various concentrations of cytisine and a further $24 \mathrm{~h}$ of incubation at $37^{\circ} \mathrm{C}$ with $5 \% \mathrm{CO}_{2}$. Cytisine at concentrations of $2.5,5$ and $10 \mathrm{mM}$ or HCPT at a concentration of $60 \mu \mathrm{M}$ was added, and the plate was incubated at $37^{\circ} \mathrm{C}$ in $5 \% \mathrm{CO}_{2}$. The HepG2 cells were resuspended with PBS at $1,500 \mathrm{rpm}$ for $10 \mathrm{~min}$ after trypsin digestion. After fixation, the cells were incubated with $200 \mu \mathrm{l}$ of Fluo3 AM $(4 \mu \mathrm{g} / \mathrm{ml})$ to detect the intracellular $\mathrm{Ca}^{2+}$ at $37^{\circ} \mathrm{C}$ at $\sim 30 \mathrm{~min}$. Next, the cells were washed twice with PBS. The fluorescence emitted by the Fluo3 AM when bound to $\mathrm{Ca}^{2+}$ ions was recorded using the laser line of $488 / 570 \mathrm{~nm}$.

Western blot analysis. Cells were harvested after the treatment with test drugs for $24 \mathrm{~h}$. After the indicated treatments, the HepG2 cells were harvested and lysed with a cell lysis solution at $4^{\circ} \mathrm{C}$ for $30 \mathrm{~min}$. Whole cellular proteins were extracted and cytosolic fractions were prepared following the procedure described by the manufacturer. Total proteins were quantitatively assayed using the BCA method. A loading buffer was added to the cytosolic extracts, and it was boiled for $10 \mathrm{~min}$. Afterwards, $50 \mu \mathrm{g}$ of protein was loaded onto a $15 \%$ sodium dodecyl sulphate-polyacrylamide gel electrophoresis (SDS-PAGE) gel and run at $80 \mathrm{~V}$ for $30 \mathrm{~min}$ and $120 \mathrm{~V}$ for $1 \mathrm{~h}$. Proteins were transferred onto nitrocellulose membranes. Afterwards, incubation was performed for $1 \mathrm{~h}$ in a blocking solution (5\% non-fat dry milk in $20 \mathrm{mM}$ of TBS with $0.1 \%$ Tween) at room temperature. Next, the membranes were gently washed with diluted TBS-T and subsequently incubated for $24 \mathrm{~h}$ with the primary antibody of GADD153 (1:500), JNK (1:500), p-JNK (1:500) and $\alpha 7-n A C h R(1: 500)$ at $4^{\circ} \mathrm{C}$, respectively. The secondary antibody was added at 1:2,000 dilutions and incubated at room temperature for $2 \mathrm{~h}$. Cell membranes were removed and coloured with DAB agent $(29,30)$. Membranes were examined via chemiluminescence detection using a photographic film. The image was captured using a Tannon gel imaging system, and the hybrid band was quantitatively analysed with Gel-Pro Analyzer 3.1 density analysis software.

Caspase activity assay. The enzymatic activity of caspase-4 was determined using a caspase colourimetric assay kit according to the manufacturer's protocol. Briefly, the cells were lysed in a lysis buffer for $15 \mathrm{~min}$ in an ice bath. The lysed cells were centrifuged at $20,000 \mathrm{x}$ g for $10 \mathrm{~min}$, and $50 \mu \mathrm{l}$ of the protein was incubated with $40 \mu \mathrm{l}$ of a reaction buffer and $10 \mu \mathrm{l}$ of the colourimetric tetrapeptides, Ac-DEVD- $p$ NA for caspase- 4 at $37^{\circ} \mathrm{C}$ for $1 \mathrm{~h}$. The optical density of the reaction mixture was quantified spectrophotometrically at a wavelength of $405 \mathrm{~nm}$. The caspase enzymatic activity in the cell lysate is directly proportional to the colour reaction.

Statistical analysis. Differences in proliferation between different cell lines were analysed using one-way ANOVA. Statistical analysis was performed using SPSS 19.0 software. (SPSS, Inc., Chicago, IL, USA). P<0.01 was considered to be a statistically significant difference.

\section{Results}

Effect of cytisine on the morphological appearance of HepG2 cells. The effect of cytisine on the ultra-structure of the HepG2 cells is shown in Fig. 1. Cells from the control group had the following characteristics: a clear structure, complete cell structure, a small number of microvilli on the cell surface, large nuclei, abundant euchromatin and obvious nucleolus. In addition, we also observed many free ribosomes, and the rough ER and mitochondria were scattered in the cytoplasm. In the positive control group, the mitochondria were reduced, and the cell processes were obviously decreased. The ER swelled 
Table I. Apoptosis rate of HepG2 cells following treatment with cytisine as detected by flow cytometry $(\mathrm{mean} \pm \mathrm{SD}, \mathrm{n}=3)$.

\begin{tabular}{lccr}
\hline Groups & Concentration & Number of cells & Apoptosis rate $(\%)$ \\
\hline Control & - & $1 \times 10^{6}$ & $0.97 \pm 0.29$ \\
HCPT & $60 \mu \mathrm{mol} / 1$ & $1 \times 10^{6}$ & $37.79 \pm 1.55^{\mathrm{a}}$ \\
Cytisine & $2.5 \mathrm{mmol} / \mathrm{l}$ & $1 \times 10^{6}$ & $10.83 \pm 0.45^{\mathrm{a}}$ \\
& $5 \mathrm{mmol} / \mathrm{l}$ & $1 \times 10^{6}$ & $16.98 \pm 1.42^{\mathrm{a}}$ \\
& $10 \mathrm{mmol} / \mathrm{l}$ & $1 \times 10^{6}$ & $34.28 \pm 1.11^{\mathrm{a}}$ \\
\hline
\end{tabular}

${ }^{\mathrm{a} C}$ Compared with control $\mathrm{P}<0.01$.
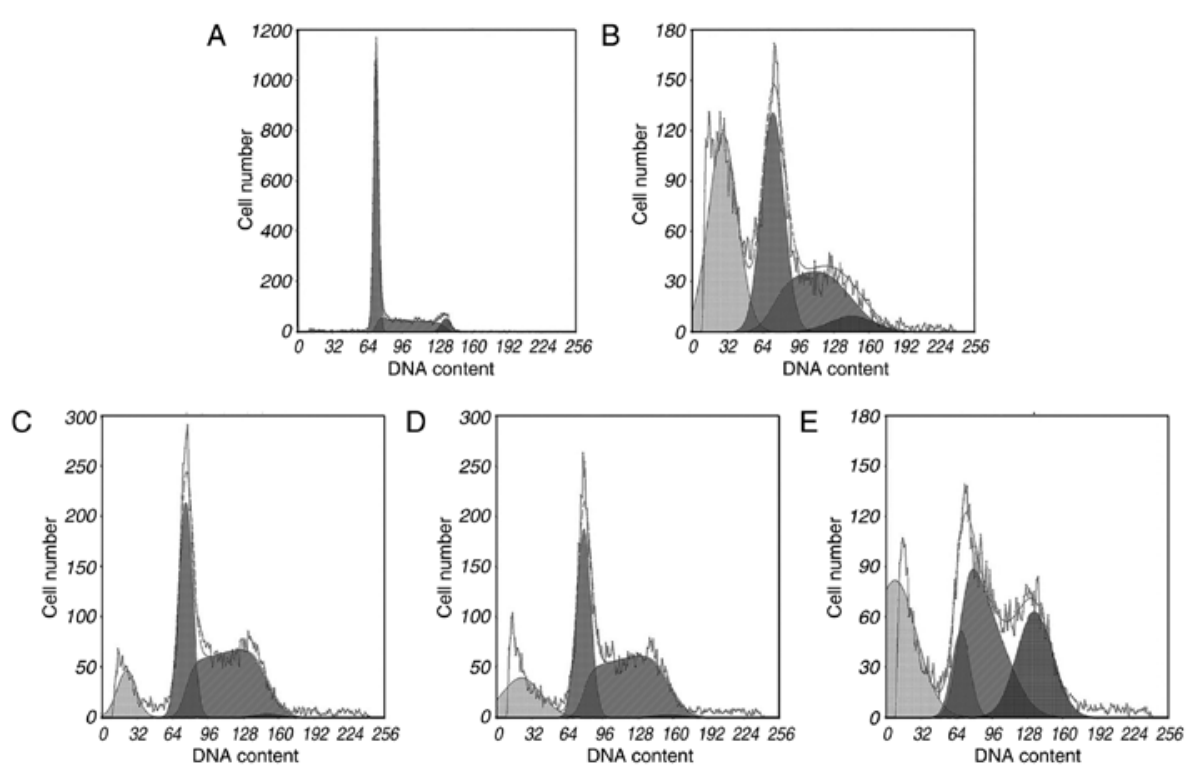

Figure 2. Apoptosis rate of HepG2 cells by flow cytometry (FCM). Cells were treated with cytisine at concentrations of $2.5,5$ and $10 \mathrm{mM}$ or HCPT at a concentration of $60 \mu \mathrm{M}$ for $24 \mathrm{~h}$. The cells were then stained with propidium iodide and analysed using an EPICS XL-MCL flow cytometer (Beckman Coulter). (A) HepG2 cells treated with RPMI-1640. (B) HepG2 cells treated with $60 \mu$ M HCPT. (C) HepG2 cells treated with 2.5 mM cytisine. (D) HepG2 cells treated with $5 \mathrm{mM}$ cytisine. (E) HepG2 cells treated with $10 \mathrm{mM}$ cytisine.

and expanded, and typical apoptotic bodies appeared. The cell surface microvilli decreased or disappeared after different concentrations of cytisine. Under electron microscopy, the apoptosis of the cells with cytoplasmic vacuolization was found to be significant. Retraction of the cytoplasm, chromatin condensation, expansion of the perinuclear space, rupture of the membrane, expansion of the ER, and swelling of the mitochondria were observed in HepG2 cells after drug treatment.

Apoptosis analysis. During apoptosis, activation of certain nucleases results in DNA degradation. The sub- $\mathrm{G}_{1}$ method relies on the fact that after DNA fragmentation, there are small fragments of DNA capable of being eluted following washing in either PBS or a specific phosphate-citrate buffer. This finding means that after staining with a quantitative DNA-binding dye, cells that have lost DNA may take up less stain and may appear to the left of the $G_{1}$ peak. Rates of apoptosis were analysed using PI staining and flow cytometric analysis. The FCM results indicated that cytisine was capable of inducing apoptosis at concentrations of $2.5,5$ and $10 \mathrm{mM}$ (Table I). In particular, HCPT induced a higher percentage $(37.79 \pm 1.55 \%)$ of apoptosis at $60 \mathrm{mM}$ compared to the control group $(\mathrm{P}<0.01)$.
Table II. Effects of cytisine on the concentration of $\left[\mathrm{Ca}^{2+}\right]_{\mathrm{i}}$ in the HepG2 cells (mean $\pm \mathrm{SD}, \mathrm{n}=3$ ).

\begin{tabular}{lcc}
\hline Groups & Concentration & $\begin{array}{c}\text { Variation in }\left[\mathrm{Ca}^{2+}\right]_{\mathrm{i}} \\
\text { (fluorescent intensity) }\end{array}$ \\
\hline Control & - & $7.39 \pm 0.17$ \\
HCPT & $60 \mu \mathrm{mol} / 1$ & $27.17 \pm 0.76^{\mathrm{a}}$ \\
Cytisine & $2.5 \mathrm{mmol} / 1$ & $17.98 \pm 0.56^{\mathrm{a}}$ \\
& $5 \mathrm{mmol} / 1$ & $21.54 \pm 0.26^{\mathrm{a}}$ \\
& $10 \mathrm{mmol} / 1$ & $30.69 \pm 0.80^{\mathrm{a}}$ \\
\hline
\end{tabular}

${ }^{\mathrm{a} C}$ Compared with control, $\mathrm{P}<0.01$.

As shown in Fig. 2, treatment with cytisine increased the percentage of cells in the sub- $\mathrm{G}_{1}$ phase $(\mathrm{P}<0.01)$. The preincubation of HepG2 cells with cytisine $(2.5,5$ and $10 \mathrm{mM})$ significantly increased the sub- $\mathrm{G}_{1}$ cell population $(\mathrm{P}<0.01)$. The data demonstrated (Table I and Fig. 2) that cytisine increased HepG2 cell apoptosis rates in a dose-dependent manner. 

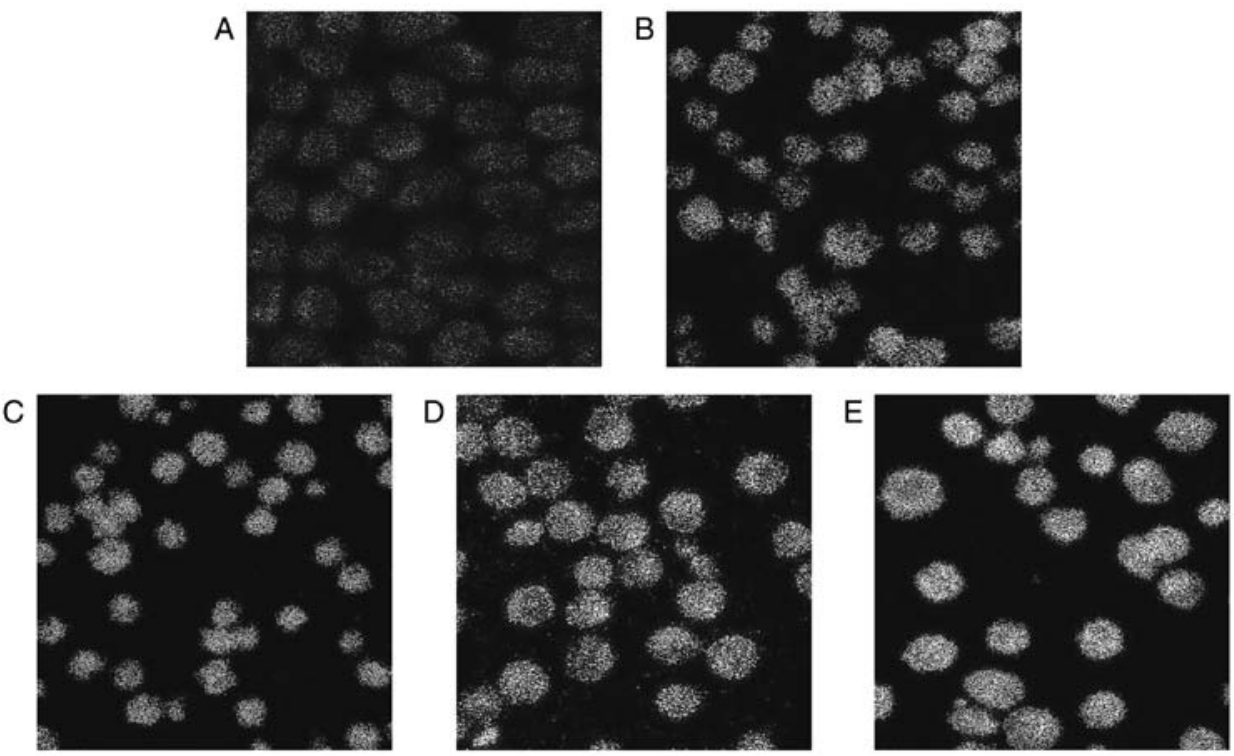

Figure 3. Concentration of $\left[\mathrm{Ca}^{2+}\right]_{\mathrm{i}}$ in HepG2 cells by laser confocal fluorescence microscopy. In all groups, cells were stained with Fluo3 AM and observed by laser confocal fluorescence microscopy. (A) HepG2 cells treated with RPMI-1640. (B) HepG2 cells treated with 2.5 mM cytisine. (C) HepG2 cells treated with $5 \mathrm{mM}$ cytisine. (D) HepG2 cells treated with $10 \mathrm{mM}$ cytisine. (E) HepG2 cells treated with $60 \mu \mathrm{M}$ HCPT.


Figure 4. Effect of cytisine on the expression level of CHOP protein in HepG2 cells. The CHOP level in HepG2 cells was determined after $24 \mathrm{~h}$ of incubation with or without cytisine treatment and HCPT by western blotting. Each blot is a representative of three similar experiments. ${ }^{* *}$ Compared with control, $\mathrm{P}<0.01$.

Laser confocal fluorescence microscopy analysis. To determine the contribution of $\mathrm{Ca}^{2+}$ released from intracellular stores to the cytisine-increased $\left[\mathrm{Ca}^{2+}\right]_{\mathrm{i}}$ content, the HepG2 cells were treated with cytisine for $24 \mathrm{~h}$. Our results clearly indicated that cytisine caused an increase in the cytoplasmic $\mathrm{Ca}^{2+}$ levels in a dose-dependent manner (Table II). Cytisine (10 mM) significantly increased the cytisine-increased $\left[\mathrm{Ca}^{2+}\right]_{\mathrm{i}}$ content by $30.69 \pm 0.80$, and cytisine $(2.5 \mathrm{mM})$ slightly increased the cytisine-increased $\left[\mathrm{Ca}^{2+}\right]_{\mathrm{i}}$ content by $17.98 \pm 0.56(\mathrm{P}<0.01)$. The green fluorescence intensity increased with the increase in drug concentration, as shown in Fig. 3.
Effects of cytisine on the expression of CHOP protein. To confirm our observation that cytisine induced ER stress, we performed immunoblotting analyses on ER-regulated protein, CHOP. CHOP level in the HepG2 cells in the cytisine group was increased compared with the normal group. Significant differences were noted ( $\mathrm{P}<0.01$, Fig. 4).

Effects of cytisine on the expression of JNK protein. Western blot analysis revealed that exposure of the HepG2 cells to cytisine for $24 \mathrm{~h}$ induced a slight upregulation of expression of the p-JNK1 and p-JNK2 proteins ( $\mathrm{P}<0.01$, Fig. 5). In contrast, 

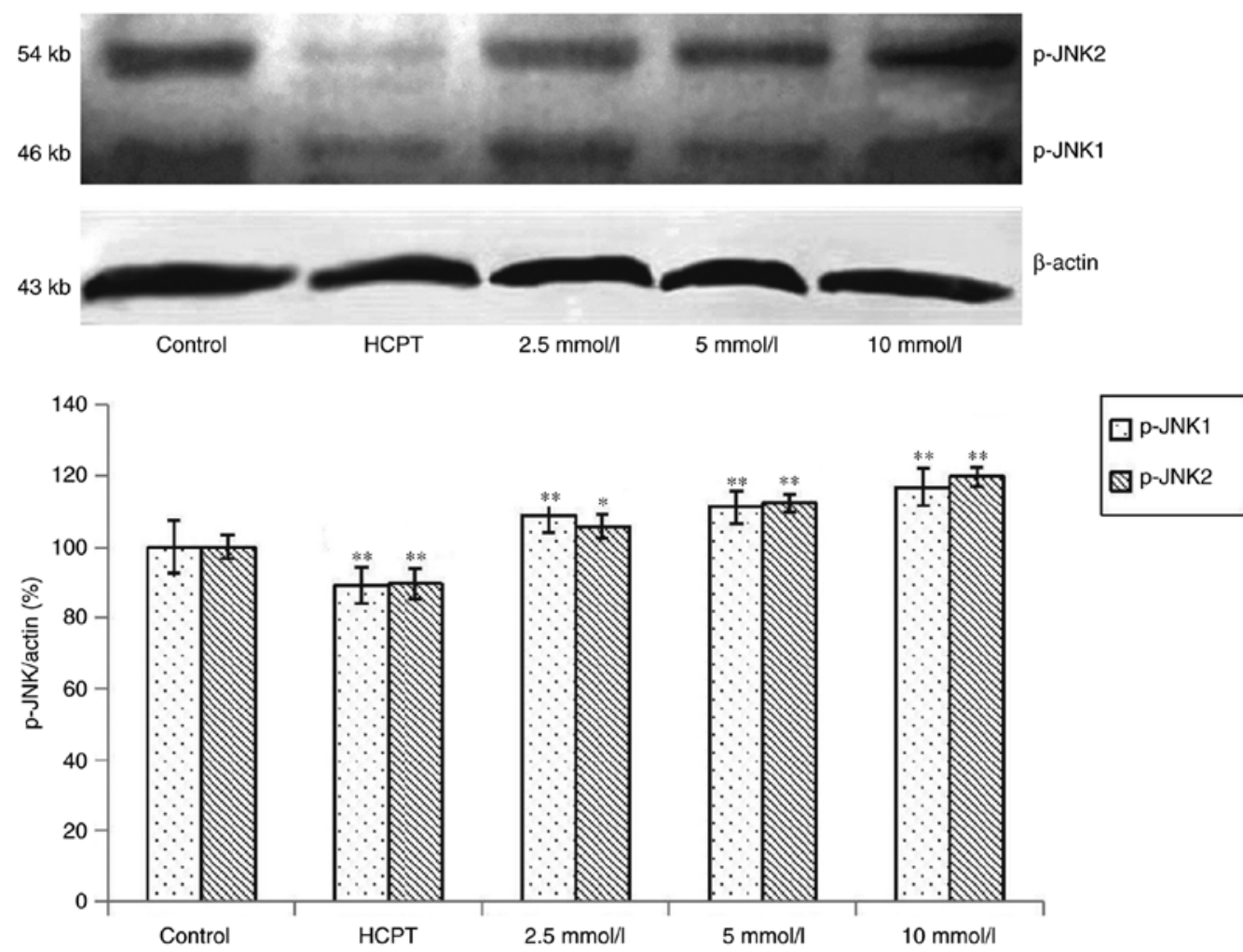

Figure 5. Effect of cytisine on the expression level of p-JNK protein in HepG2 cells. Expression levels of p-JNK1 and p-JNK2 proteins. After treatment, the fractions were resolved by SDS-PAGE, transferred onto nitrocellulose membranes, and probed with primary antibody for p-JNK and secondary antibody for $\operatorname{IgG}(\mathrm{H}+\mathrm{L})$. The amount of $\beta$-actin was measured as an internal control. "Compared with control, $\mathrm{P}<0.05 ;{ }^{* * *}$ compared with control, $\mathrm{P}<0.01$.


Figure 6. Effect of cytisine on the expression level of JNK protein in HepG2 cells. Expression levels of JNK1/2 proteins. After treatment, the fractions were resolved by SDS-PAGE, transferred onto nitrocellulose membranes, and probed with the primary antibody for JNK and secondary antibody for IgG (H+L). The amount of $\beta$-actin was measured as an internal control. ${ }^{* *}$ Compared with control, $\mathrm{P}<0.01$.

the expression levels of JNK1 and JNK2 were significantly increased in the HepG2 cells in a dose-dependent manner (P<0.01, Fig. 6).
Effect of cytisine on the activation of caspase-4. As shown in Table III, after treatment of the HepG2 cells with cytisine for $24 \mathrm{~h}$, the activities of caspase- 4 were significantly increased 
Table III. Effects of cytisine on caspase-4 activity in the HepG2 cells (mean \pm SD, $n=3$ ).

\begin{tabular}{lccrr}
\hline Groups & Concentration & OD value $(\bar{x} \pm \mathrm{s})$ & pNA $(\mu \mathrm{M})$ & Caspase-4 activity $(\%)$ \\
\hline Control & - & $0.1093 \pm 0.006$ & 29.25 & - \\
HCPT & $60 \mu \mathrm{mol} / 1$ & $0.3177 \pm 0.008^{\mathrm{a}}$ & 81.35 & 178.12 \\
Cytisine & $2.5 \mathrm{mmol} / 1$ & $0.1500 \pm 0.325^{\mathrm{a}}$ & 39.43 & 34.79 \\
& $5 \mathrm{mmol} / 1$ & $0.2337 \pm 0.007^{\mathrm{a}}$ & 60.35 & 106.32 \\
& $10 \mathrm{mmol} / 1$ & $0.3247 \pm 0.007^{\mathrm{a}}$ & 83.10 & 184.10 \\
\hline
\end{tabular}

${ }^{\mathrm{a} C}$ Compared with control $\mathrm{P}<0.01$.


Figure 7. Effect of cytisine on the expression level of $\alpha 7-n A C h R$ protein in HepG2 cells. Expression levels of $\alpha 7$-nAChR were determined by western blotting. After treatment, the fractions were resolved by SDS-PAGE, transferred onto nitrocellulose membranes, and probed with primary antibody for $\alpha 7$-nAChR and secondary antibody of $\operatorname{IgG}(\mathrm{H}+\mathrm{L})$. The amount of $\beta$-actin was measured as an internal control. ${ }^{* *}$ Compared with control, $\mathrm{P}<0.01$.

compared with the control group $(\mathrm{P}<0.01)$. Cytisine led to a significant increase in the level of caspase- 4 and significant upregulation of caspase-4 expression.

Effects of the expression of $\alpha 7-n A C h R$ protein in Hep 2 cells. To examine the $\alpha 7-n A C h R$ expression induced by the overloading of $\mathrm{Ca}^{2+}$, western blot experiments were conducted. As shown in Fig. 7, the $\alpha 7-n A C h R$ expression level was significantly increased by treatment with $10 \mathrm{mM}$ of cytisine for $24 \mathrm{~h}$ compared with the control group $(\mathrm{P}<0.01)$. Western blot analysis revealed that the exposure of the HepG2 cells to HCPT for $24 \mathrm{~h}$ induced a slight upregulation of the expression of the $\alpha 7-n A C h R$ protein compared with the control group. The expression levels of $\alpha 7-n A C h R$ were significantly upregulated in the HepG2 cells in a dose-dependent manner $(\mathrm{P}<0.01)$.

\section{Discussion}

Apoptosis induction is one of the mechanisms proposed for the anticancer therapeutic effects of cytisine. Our team previously confirmed that cytisine could induce apoptosis in HepG2 cells via a mitochondrial pathway (31). However, the molecular mechanisms of the effects of ER stress due to cytisine have not been thoroughly elucidated to date. ER stress, a newly defined signalling pathway, initiates apoptosis (32-34). In the present study, we demonstrated that $\mathrm{Ca}^{2+}$ overload induced by cytisine promoted endoplasmic reticulum (ER) stress, consequently leading to HepG2 cell apoptosis. In a previous study, we showed that cytisine, which is a naturally occurring quinolizidine alkaloid, had an anticancer effect. Our prior MTT assay investigation proved that cytisine could inhibit the proliferation of human HepG2 cells in a dose-dependent manner (31). 
In the present study, morphological changes of apoptotic cells were observed after treatment with different concentrations of cytisine. Cell surface microvilli decreased and disappeared with an increase in drug concentration. Different amounts of spherical protrusions, apoptotic bodies, cell membrane rupture and cytoplasm overflow were observed in the apoptotic cells with transmission electron microscopy. ER dilatation and mitochondrial swelling were observed in the HepG2 cells after a high dose of cytisine. In the positive control group, the mitochondria were reduced, and the cell processes were obviously decreased. Typical apoptotic cells and apoptotic bodies were observed in the HepG2 cells. These results suggested that cytisine induces the apoptosis of the HepG2 cells (Fig. 1).

The ER is associated with protein synthesis, post-translational modification, and absorption and release of calcium ions. However, when the quality control system is overloaded under various stresses, including disruption of $\mathrm{Ca}^{2+}$ homeostasis, ER functions are impaired, and unfolded proteins are accumulated in the ER lumen. This situation is called ER stress. The ER is the primary site of intracellular $\mathrm{Ca}^{2+}$ storage (35-37). Calcium homeostasis is central to all cellular functions and has been studied for decades (38-40). $\mathrm{Ca}^{2+}$ is a critical second messenger that mediates many physiological cellular signalling pathways (41). The ER controls the calcium ion through the ryanodine receptor, inositol triphosphate receptor and sarco/endoplasmic reticulum $\mathrm{Ca}^{2+}$-ATPase (41). Moreover, research has clearly confirmed that $\left[\mathrm{Ca}^{2+}\right]_{\mathrm{i}}$ accumulation contributes to cell death (42). Studies have shown that cytisine can give rise to $\mathrm{Ca}^{2+}$ overload (43). Whether $\mathrm{Ca}^{2+}$ overload induced by cytisine activates apoptosis in HepG2 cells remained undetermined. We hypothesized that cytisine stimulation would cause ER stress due to $\mathrm{Ca}^{2+}$ overload, leading to apoptosis. To determine whether the effects of cytisine on ER resulted in apoptosis, HepG2 cells were treated for $24 \mathrm{~h}$ with various concentrations of cytisine. Flow cytometry with PI staining revealed that the drug treatment increased the proportion of apoptotic cells (Table I and Fig. 2), confirming the cytisine-induced apoptosis in HepG2 cells. Next, laser confocal fluorescence microscopy was used to examine the intracellular $\mathrm{Ca}^{2+}$ concentration. Our data showed that cytisine increased the intracellular $\mathrm{Ca}^{2+}$ concentration in a cytisine-dependent manner (Table II and Fig. 3). These results suggested that cytisine increased the intracellular $\mathrm{Ca}^{2+}$ concentration by releasing $\mathrm{Ca}^{2+}$ from the ER, thereby causing ER stress. These findings revealed that calcium as a starting factor could induce ER stress, resulting in HepG2 cell apoptosis. It was concluded that HepG2 cellular exposure to cytisine resulted in a direct and immediate consequence of $\mathrm{Ca}^{2+}$ overload that led to disturbance in $\mathrm{Ca}^{2+}$ homeostasis in the ER, which caused ER stress leading to apoptosis.

When ER stress is prolonged, pro-apoptotic signaling pathways are activated, such as the CCAAT/enhancer-binding protein (C/EBP) and homologous protein (CHOP/GADD153), caspase-12 and JNK-dependent pathways $(44,45)$. The caspase family plays an important role in apoptosis. Previous research has shown that caspase-12 is involved in ER-mediated apoptosis (46). Overexpression of caspase-12 only occurs during ER stress. It has been reported that caspase-12 triggers cellular apoptosis through the caspase-9/caspase-3 pathway. Cleaved caspase-12 reportedly activates caspase- 9 , followed by activation of caspase-3 $(47,48)$. In a previous study, we found that human caspase- 4 , one of the closest paralogs of rodent caspase-12, plays an important role in cell death via ER stress. However, the relevance of caspase-12 to ER-induced apoptosis has been questioned due to the absence of caspase-12 in most humans (49). Upregulation of caspase-4 in HepG2 cells had been demonstrated in the present study. When cells were incubated with cytisine, the expression of caspase- 4 was significantly higher than that noted in the control (Table III). Thus, we concludes that caspase- 4 plays an important role in cytisine-induced apoptosis that is associated with ER stress. It is suggested that $\mathrm{Ca}^{2+}$ overload, as an apoptosis-inducing factor, may cause ER stress to increase caspase- 4 expression, which ultimately activates caspase-3 (this result has been confirmed by our team) (31), leading to apoptosis.

Another mediator of programmed cell death in ER-stressed cells is the transcription factor, CHOP. In line with previous reports, we found that significant overexpression of CHOP/GADD153 promotes cell death or DNA damage (50). Elevated levels of CHOP can promote the transcription of Bim, BAX and DR5 while suppressing the induction of Bcl-2 in ER stress (51). In addition, upregulation of the expression of CHOP is involved in caspase activation and mitochondrial events (50). In the present study, the expression of CHOP (Fig. 4) was continuously increased after cytisine treatment in the HepG2 cells. In the present study, calcium overload was hypothesized to result in a high expression of the CHOP gene, which promoted the accumulation of Bim, BAX and DR5 while suppressing the induction of $\mathrm{Bcl}-2$. Indeed, upregulation of the expression of CHOP is involved in ER stress-induced apoptosis, and although it is normally undetectable in proliferating cells, it becomes highly synthesized in cells exposed to cytisine that perturb the homeostasis of the ER, which is linked to the development of apoptosis.

JNK, a member of the Ser/Thr protein kinase family, is induced by stress conditions, such as ER stress (52). Additionally, JNK participates in cell proliferation, survival, and apoptosis (53). It has been confirmed by previous research that inhibition of JNK phosphorylation results in decreased levels of ER stress-induced caspase-3/-7 (54). JNK, which has three isoforms, i.e., JNK1, JNK2 and JNK3, is also one of the signaling pathways of ER. JNK1 and JNK2 are associated with cell death and play an important role in apoptosis (55). To investigate the role of JNK in ER stress that is induced by cytisine, western blotting was used to examine expression levels of JNK1/2 and p-JNK1/2. We found that the expression levels of p-JNK1 and p-JNK2 were significantly enhanced in HepG2 cells in a dose-dependent manner (Fig. 5). JNK1/2 was increased by cytisine treatment (Fig. 6). These results suggested that c-Jun phosphorylation by $\mathrm{Ca}^{2+}$ overload in the HepG2 cells was mainly associated with JNK1/2. Our data suggested that the ER stress-JNK pathway is involved in $\mathrm{Ca}^{2+}$ overload and that cytisine induced ER stress via $\mathrm{Ca}^{2+}$ overload, thereby promoting cell death due to subsequent JNK activation.

nAChRs play an important role in synaptic transmission; thus, the primary focus of nicotine and its receptors has been its physiological effects within the nervous system. However, there is growing evidence suggesting that $\mathrm{nAChRs}$ are not 
only expressed in the nervous system but also in nonneuronal cells, including cancer cells $(23,56)$. In support of our findings, gastric, bladder, colon and non-small lung cancer cells have been shown to express $\mathrm{nAChR}$ subunits, and nicotine has been shown to be mitogenic for vascular smooth muscle cells (57). nAChRs are known to play several important roles in cancer cells, such as proliferation, inflammation, angiogenesis and invasion $(58,59)$. Thus, the expression of nAChRs in non-neuronal cells indicates that they possess functions independent of neurotransmission. Therefore, nAChRs are viewed as a novel drug target for the treatment of cancer. Current research indicates that the $\alpha-7$ nicotinic receptor, which is one of the various types of subunits, is related to intracellular $\mathrm{Ca}^{2+}$ overload (60). However, the actual role of the $\alpha-7$ nicotinic receptor in HepG2 cells is unknown. Determining the relationship between the calcium ion concentration and $\alpha 7-n A C h R$ in HepG2 cells is crucial. Our data indicated that $\alpha 7-n A C h R$ was expressed at a high level under cytisine conditions (Fig. 7). After the cells were treated with cytisine, an increase in intracellular calcium concentration in the HepG2 cells was noted suggesting that intracellular $\mathrm{Ca}^{2+}$ overload was related to the upregulation of the expression of $\alpha 7-\mathrm{nAChR}$. As a result, cytisine, which is a partial agonist to nicotinic acetylcholine, has a high affinity to $\alpha 7-n A C h R$. Cytisine activates nAChRs, and the confocal laser scanning results indicated that cytisine can induce HepG 2 cell calcium overload. The results of the present study showed that cytisine activates nicotinic acetylcholine leading to calcium overload. However, the specific relevance between nicotinic acetylcholine activation and $\mathrm{Ca}^{2+}$ overload remains to be studied.

Our team previously confirmed that cytisine induced apoptosis of HepG2 cells via the mitochondrial pathway. Following treatment with cytisine, mitochondrial permeability may increase, which may subsequently lead to mitochondrial matrix expansion, outer membrane rupture and the release of cytochome $c$. In addition, a previous study confirmed that increased cytochome $c$ release into the cytoplasm caused activation of caspase-3 (31). The present study investigated whether cytisine induced apoptosis via the ER pathway.

In summary, the results of the present study indicate that cytisine induces the apoptosis of tumourcells via an ER pathway. Our data clearly suggest that calcium overload promotes ER stress-induced apoptosis in cytisine-induced HepG2 cells, which occurs through modulating the CHOP/GADD153, JNK and caspase-4 pathways. Finally, the caspase cascade is activated to induce apoptosis of HepG2 cells. Cytisine has affinity to nAChRs, and it can activate $\alpha 7-n A C h R$ expression. In conclusion, cytisine induced ER stress-mediated apoptotic pathway by activating CHOP, JNK and caspase-4 in HepG2 cells.

\section{Acknowledgements}

The present study was supported in part by the Open Research Program for the Key Laboratory of College of Heilongjiang Province (China) (CPAT-2012003), the Natural Science Item of the Department of Education of Heilongjiang Province (China) (12541205), Innovation Talents Item of Science and Technology of Harbin City (China) (2014RFQXJ154), the Doctoral Research Project of Harbin University of Commerce
(12DL008), the Graduate Students Innovative Research Project of Harbin University of Commerce (YJSCX2015-390HSD), 2016 Harbin University of Commerce Youth Innovation Talent Support Program (grant no. 2016QN057), and the Scientific Research Team Program of Harbin University of Commerce (grant no. 2016TD002).

\section{References}

1. Zhang PP, Wang PQ, Qiao CP, Zhang Q, Zhang JP, Chen F, Zhang X, Xie WF, Yuan ZL, Li ZS and Chen YX: Differentiation therapy of hepatocellular carcinoma by inhibiting the activity of AKT/GSK-3 $\beta / \beta$-catenin axis and TGF- $\beta$ induced EMT with sophocarpine. Cancer Lett 376: 95-103, 2016.

2. Liang L, Wang XY, Zhang XH, Ji B, Yan HC, Deng HZ and Wu XR: Sophoridine exerts an anti-colorectal carcinoma effect through apoptosis induction in vitro and in vivo. Life Sci 91: 1295-1303, 2012

3. Li YJ, Yang Q, Zhang K, Guo YY, Li XB, Yang L, Zhao MG and Wu YM: Cytisine confers neuronal protection against excitotoxic injury by down-regulating GluN2B-containing NMDA receptors. Neurtoxicology 34: 219-225, 2013.

4. Lin Z, Huang CF, Liu XS and Jiang J: In vitro anti-tumour activities of quinolizidine alkaloids derived from Sophora flavescens Ait. Basic Clin Pharmacolo Toxicol 108: 304-309, 2011.

5. Malhi $\mathrm{H}$ and Kaufman RJ: Endoplasmic reticulum stress in liver disease. J Hepatol 54: 795-809, 2011.

6. Lenna S and Trojanowska M: The role of endoplasmic reticulum stress and the unfolded protein response in fibrosis. Curr Opin Rheumatol 24, 2012

7. Friedman SL: Mac the knife? Macrophages-the double-edged sword of hepatic fibrosis. J Clin Invest 115: 29-32, 2005.

8. Tabas I and Ron D: Integrating the mechanisms of apoptosis induced by endoplasmic reticulum stress. Nat Cell Biol 13: 184-190, 2011.

9. Urra H, Dufey E, Lisbona F, Rojas-Rivera D and Hetz C: When ER stress reaches a dead end. Biochim Biophys Acta 1833: 3507-3517, 2013

10. Farrukh MR, Nissar UA, Afnan Q, Rafiq RA, Sharma L, Amin S, Kaiser P, Sharma PR and Tasduq SA: Oxidative stress mediated $\mathrm{Ca}^{2+}$ release manifests endoplasmic reticulum stress leading to unfolded protein response in UV-B irradiated human skin cells. J Dermatol Sci 75: 24-35, 2014

11. Zhu M, Zhou S, Huang Z, Wen J and Li H: $\mathrm{Ca}^{2+}$-dependent endoplasmic reticulum stress regulates mechanical stress regulates mechanical stress-mediated cartilage thinning. J Dent Res 95: 889-896, 2016.

12. Biagioli M, Pifferi S, Ragghianti M, Bucci S, Rizzuto R and Pinton P: Endoplasmic reticulum stress and alteration in calcium homeostasis are involved in cadmium-induced apoptpsis. Cell Calcium 43: 184-195, 2007.

13. Wan S and Jiang L: Endoplasmic reticulum (ER) stress and the unfolded protein response (UPR) in plants. Protoplasma 253: 753-764, 2016.

14. Li K, Zhang L, Xiang X, Gong S, Ma L, Xu L, Wang G, Liu Y, Ji X, Liu S, et al: Arsenic trioxide alleviates airway hyperresponsiveness and promotes apoptosis of $\mathrm{CD}^{+} \mathrm{T}$ lymphocytes: Evidence for involvement of the ER stress-CHOP pathway. Ir J Med Sci 182: 573-583, 2013.

15. Li J and Holbrook NJ: Elevated gadd153/chop expression and enhanced c-Jun N-terminal protein kinase activation sensitizes aged cells to ER stress. Exp Gerontol 39: 735-744, 2004.

16. Momoi T: Caspases involved in ER stress-mediated cell death. J Chem Neuroanat 28: 101-105, 2004.

17. Zhang Q, Liu J, Chen S, Liu J, Liu L, Liu G, Wang F, Jiang W, Zhang C, Wang $S$ and Yuan X: Caspase- 12 is involved in stretch-induced apoptosis mediated endoplasmic reticulum stress. Apoptosis 21: 432-442, 2016.

18. Hetz C, Russelakis-Carneiro M, Maundrell K, Castilla J and Soto C: Caspase-12 and endoplasmic reticulum stress mediate neurotoxicity of pathological prion protein. EMBO J 22: 5435-5445, 2003

19. Hitomi J,Katayama T,Eguchi Y, Kudo T, Taniguchi M,Koyama Y, Manabe T, Yamagishi S, Bando Y, Imaizumi K, et al: Involvement of caspase- 4 in endoplasmic reticulum stress-induced apoptosis and Abeta-induced cell death. J Cell Biol 165: 347-356, 2004. 
20. Walker N, Howe C, Glover M, McRobbie H, Barnes J, Nosa V, Parag V, Bassett B and Bullen C: Cytisine versus nicotine for smoking cessation. N Engl J Med 371: 2353-2362, 2014.

21. Ponzoni L, Braida D, Pucci L, Andrea D, Fasoli F, Manfredi I, Papke RL, Stokes C, Cannazza G, Clementi F, et al: The cytisine derivatives, $\mathrm{CC} 4$ and $\mathrm{CC} 26$, reduce nicotine-induced conditioned place preference in zebrafish by acting on heteromeric neuronal nicotinic acetylcholine receptors. Psychopharmacology 231: 4681-4693, 2014.

22. Radchenko EV, Dravolina OA and Bespalov AY: Agonist and antagonist effects of cytisine in vivo. Neuropharmacology 95: 206-214, 2015

23. Wessler I and Kirkpatrick CJ: Acetylcholine beyond neurons: The non-neuronal cholinergic system in humans. Br J Pharmacol 154: 1558-1571, 2008.

24. Séguéla P, Wadiche J, Dineley-Miller K, Dani JA and Patrick JW: Molecular cloning, functional properties, and distribution of rat brain alpha 7: A nicotinic cation channel highly permeable to calcium. J Neurosci 13: 596-604, 1993.

25. Guerra-Álvarez M, Moreno-Ortega AJ, Navarro E, Fernández-Morales JC, Egea J, López MG and Cano-Abad MF: Positive allosteric modulation of alpha-7 nicotinic receptors promotes cell death by inducing $\mathrm{Ca}^{2+}$ release from the endoplasmic reticulum. J Neurochem 133: 309-319, 2015.

26. Levine DS, Rubin CE, Reid BJ and Haggitt RC: Specialized metaplastic columnar epithelium in Barrett's esophagus. A comparative transmission electron microscopic study. Lab Invest 60: 418-432, 1989.

27. Kawamoto K, Kawakami K, Kawamura Y, Matsumura $\mathrm{H}$ and Ohyama A: New sensitivity test using flow cytomety. J Neurooncol 6: 361-370, 1988

28. Lev-Ram V and Ellisman MH: Axonal activation-induced calcium transients in myelinating Schwann cells, cells, andmechanisms. J Neurosci 15: 2628-2637, 1995.

29. Towbin H, Staehelin T and Gordon J: Electrophoretic transfer of proteins from polyacrylamide gels to nitrocellulose sheets: Procedure and some applications. Proc Natl Acad Sci USA 76 : 4350-4354, 1979.

30. Burnette WN: 'Western blotting': Electrophoretic transfer of proteins from sodium dodecyl sulfate-polyacrylamide gels to unmodified nitrocellulose and radiographic detection with antibody and radioiodinated protein A. Anal Biochem 112: 195-203, 1981.

31. Yu L, Wang X, Chen ZF, Jing B, Shang DY, Sun YX, Yang JH, Zhang LF and Ji YB: Cytisine induces apoptosis of HepG2 cells. Mol Med Rep 16: 3363-3370, 2017.

32. Winter E, Chiaradia LD, Silva AH, Nunes RJ, Yunes RA and Creczynski-Pasa TB: Involvement of extrinsic and intrinsic apoptotic pathways together with endoplasmic reticulum stress in cell death induced by naphthylchalcones in a leukemic cell line: Advantages of multi-target action. Toxicol In Vitro 28: 769-777, 2014.

33. Kawaguchi T, Miyazawa K, Moriya S, Ohtomo T, Che XF, Naito $M$, Itoh $M$ and Tomoda A: Combined treatment with bortezomib plus bafilomycin A enhances the cytocidal effect and induces endoplasmic reticulum stress in U266 myeloma cells: Crosstalk among proteasome, autophagy-lysosome and ER stress. Int J Oncol 38: 643-654, 2011.

34. Zhu J, Chen M, Chen N, Ma A, Zhu C, Zhao R, Jiang M, Zhou J, Ye L, Fu $\mathrm{H}$ and Zhang X: Glycyrrhetinic acid induces G1-phase cell cycle arrest in human non-small cell lung cancer cells through endoplasmic reticulum stress pathway. Int J Oncol 46: 981-988, 2015.

35. Isomura M, Kotake Y, Masuda K, Miyara M, Okuda K, Samizo S, Sanoh S, Hosoi T, Ozawa K and Ohta S: Tributyltin-induced endoplasmic reticulum stress and its $\mathrm{Ca}^{2+}$-mediated mechanism. Toxicol Appl Pharmacol 272: 137-146, 2013.

36. Nyberg WA and Espinosa A: Imiquimod induces ER stress and $\mathrm{Ca}^{2+}$ influx independently of TLR7 and TLR8. Biochem Biophysl Res Commun 473: 789-794, 2016.

37. Kaufman RJ and Malhotra JD: Calcium trafficking integrates endoplasmic reticulum function with mitochondrial bioenergetics. Biochim Biophys Acta 1843: 2233-2239, 2014.

38. Ahn C, An BS and Jeung EB: Streptozotocin induces endoplasmic reticulum stress and apoptosis via disruption of calcium homeostasis in mouse pancreas. Mol Cell Endocrinol 412: 302-308, 2015

39. Verkhratsky A and Toescu EC: Endoplasmic reticulum $\mathrm{Ca}^{2+}$ homeostasis and neuronal death. J Cell Mol Med 7: 351-361, 2003 .
40. Song YF, Luo Z, Zhang LH, Hogstrand C and Pan YX: Endoplasmic reticulum stress and disturbed calcium homeostasis are involved in copper-induced alteration in hepatic lipid metabolism in yellow cafish Pelteobagrus fulvidraco. Chemosphere 144: 2443-2453, 2016.

41. Ermak G and Davies KJ: Calcium and oxidative stress: From cell signaling to cell death. Mol Immunol 38: 713-721, 2001.

42. Sun DP, Li XX, Liu XL, Zhao D, Qiu FQ, Li Y and Ma P: Gypenosides induce apoptosis by $\mathrm{Ca}^{2+}$ overload mediated by endoplasmic-reticulum and store-operated $\mathrm{Ca}^{2+}$ channels in human hepatoma cells. Cancer Biother Radiopharm 28: 320-326, 2013.

43. Sciamanna MA, Griesmann GE, Williams CL and Lennon VA: Nicotinic acetylcholine receptors of muscle and neuronal (alpha7) types coexpressed in a small cell lung carcinoma. J Neurochem 69: 2302-2311, 1997.

44. Lakshmanan AP, Thandavarayan RA, Palaniyandi SS, Sari FR, Meilei H, Giridharan VV, Soetikno V, Suzuki K, Kodama M and Watanabe K: Modulation of AT-1R/CHOP-JNK-Caspase12 pathway by olmesartan treatment attenuates ER stress-induced renal apoptosis in streptozotocin-induced diabetic mice. Eur J Pharm Sci 44: 627-634, 2011.

45. Huang Y, Li X, Wang Y, Wang H, Huang C and Li J: Endoplasmic reticulum stress-induced hepatic stellate cell apoptosis through calcium-mediated JNK/P38 MAPK and calpain/caspase-12 pathways. Mol Cell Biochem 394: 1-12, 2014.

46. Rao RV, Castro-Obregon S, Frankowski H, Schuler M, Stoka V, del Rio G, Bredesen DE and Ellerby HM: Coupling endoplasmic reticulum stress to the cell death program. An Apaf-1-independent intrinsic pathway. J Biol Chem 277: 21836-21842, 2002.

47. Chow SE, Kao CH, Liu YT, Cheng ML, Yang YW, Huang YK, Hsu CC and Wang JS: Resveratrol induced ER expansion and ER caspase-mediated apoptosis in human nasopharyngeal carcinoma cells. Apoptosis 19: 527-541, 2014

48. Nakagawa T, Zhu H, Morishima N, Li E, Xu J, Yankner BA and Yuan J: Caspase-12 mediates endoplasmic-reticulum-specific apoptosis and cytotoxicity by amyloid-beta. Nature 403: 98-103, 2000.

49. Fischer H, Koenig U, Eckhart L and Tschachler E: Human caspase 12 has acquired deleterious mutations. Biochem Biophys Res Commun 293: 722-726, 2002.

50. Oyadomari S and Mori M: Roles of CHOP/GADD153 in endoplasmic reticulum stress. Cell Death Differ 11: 381-389, 2004.

51. Komatsu S, Miyazawa K, Moriya S, Takase A, Naito M, Inazu M, Kohno N, Itoh $\mathrm{M}$ and Tomoda A: Clarithromycin enhances bortezomib-induced cytotoxicity via endoplasmic reticulum stress-mediated CHOP (GADD153) induction and autophagy in breast cancer cells. Int J Oncol 40: 1029-1039, 2012.

52. Wang SF, Yen JC, Yin PH, Chi CW and Lee HC: Involvement of oxidative stress-activated JNK signaling in the methamphetamine-induced cell death of human SH-SY5Y cells. Toxicology 246: 234-241, 2008.

53. Junttila MR, Li SP and Westermarck J: Phosphatase-mediated crosstalk between MAPK signaling pathways in the regulation of cell survival. FASEB J 22: 954-965, 2008.

54. Rius B, López-Vicario C, González-Périz A, Morán-Salvador E, García-Alonso V, Clária $\mathbf{J}$ and Titos E: Resolution of inflammation in obesity-induced liver disease. Front Immunol 3: 257, 2012.

55. Du K, Takahashi T, Kuge S, Naganuma A and Hwang GW: FBVO6 attenuates cadmium toxicity in HEK293 cells by inhibiting ER stress and JNK activation. J Toxicol Sci 39: 861-866, 2014.

56. Bierut LJ: Nicotine dependence and genetic variation in the nicotinic receptors. Drug Alcohol Depend 104 (Suppl 1): S64-S69, 2009.

57. Catassi A, Servent D, Paleari L, Cesario A and Russo P: Multiple roles of nicotine on cell proliferation and inhibition of apoptosis: Implications on lung carcinogenesis. Mutat Res 659: 221-231, 2008.

58. Hecht SS: Tobacco carcinogens, their biomarkers and tobacco-induced cancer. Nat Rev Cancer 3: 733-744, 2003.

59. Ng MK, Wu J, Chang E, Wang BY, Katzenberg-Clark R, Ishii-Watabe A and Cooke JP: A central role for nicotinic cholinergic regulation of growth factor-induced endothelial cell migration. Arterioscler Thromb Vasc Biol 27: 106-112, 2007.

60. del Barrio L, Egea J, León R, Romero A, Ruiz A, Montero M, Alvarez J and López MG: Calcium signalling mediated through $\alpha 7$ and non- $\alpha 7 \mathrm{nAChR}$ stimulation is differentially regulated in bovine chromaffin cells to induce catecholamine release. Br J Pharmacol 162: 94-110,2011. 